\title{
Research on the task design and incentive approach for the state-owned enterprise project managers
}

\author{
Ying Yang* \\ International Business School \\ Yunnan University of Finance and Economics \\ Kunming, China \\ 11476423@qq.com \\ $\mathrm{Lu} \mathrm{He}$ \\ Xiamen City Land Development Corp.
}

\author{
Xiamen, China \\ 84451591@qq.com
}

\author{
Feng Ma* \\ Information School \\ Yunnan University of Finance and Economics \\ Kunming, China \\ 375090618@qq.com
}

\begin{abstract}
With the implementation of the belt and road strategy, more and more state-owned enterprises go abroad and participate in international competition and cooperation. Because of its traditional mechanism, the incentive mechanism for project managers of state-owned enterprises faces with significant challenges. Because of their work level, political consciousness and working environments, the state-owned enterprise project managers are deemed to be a special group among project managers. Based on the job characteristics model, this paper examines the effect of the specific dimensions of the job characteristics model on the state-owned enterprise project managers' work emotions, work attitudes, work behavior and work role performance through the questionnaire survey, variable correlation analysis and regression analysis. It is finally proved that the JCM-based task design indeed has positive effects on the state-owned enterprise project managers' work behavior and work performance. This is helpful for the state-own enterprises to design incentive models for their project managers and provides valuable implications for enterprises to effectively manage their core project talents and ultimately helps increase the managing efficiency for the government project management and the state-owned enterprise management.
\end{abstract}

Keywords- project managers; job characteristics model; task design; incentive model

\section{INTRODUCTION}

The project manager is the direct manager of the construction project. His/her management and innovation ability, work enthusiasm, sense of responsibility, moral consciousness and loyalty to the enterprise will directly affect and determine the quality, safety, construction efficiency and cost of the project. The state-owned enterprise project managers are much more qualified than those of other enterprises. They have high education background and many years of working experience in large projects. And more importantly, they have many years of working experience in the field of government construction projects, so they have higher professional skills, stronger management skills, more working experience and higher social skills. They can be said to be a combination of high professional skills, high management skills, high public relation skills and high political consciousness. Their work value is quite different from that of other staff. Work for them is not only a way to make a living but also a way to achieve self-worth. They may have some different views or requirements on the enterprises' management practices and management behavior, so they are very likely to express their dissatisfaction with the enterprises in other covert manners, which may make them come into conflict with the enterprises.

The conflict between the project managers and the enterprises is a process that the project managers continuously accumulate their negative emotions on organizations. At first, most of the conflicts are expressed in covert manners, known as covert conflicts, such as slacking on work, malpractice, immorality and so on, and then they will be expressed in overt manners, known as overt conflicts, such as resignation or applying for working in a different work unit. However, covert conflicts can have disastrous effects on an organization. The current relevant state laws and regulations have not clearly defined the scope of the project managers' responsibility, so enterprises and relevant departments still have a pretty poor understanding of the project managers' role. As a result, they cannot effectively manage the project managers and neither can the government departments. So the project manager management is a subject that the enterprises and government should list as their priority task.

\section{LITERATURE REVIEW}

Job characteristics model is an important theoretical base for work design and redesign. It got its first appearance in the work by Herzberg (1966) [1], Tuner and Lawrence (1965) [2] and Blood and Hulin (1967) [3]. In 1971, Hackman and Lawler [4] proposed that the core job characteristics consisted of six dimensions: Skill Variety, Task Identity, Autonomy, Feedback, Cooperation and Friendship Opportunities. Later, in their own research, friendship opportunities and cooperation factors were deleted, and the importance of tasks and two kinds of feedback were put forward. On the basis of the research mentioned above, Hackman and Lawler proposed the theory, namely, the task itself should consist of some basic characteristics which could boost the employees' work motivation.

*Corresponding author 
The Job Diagnostic Survey (JDS), developed by Hackman and Lawler, can be directly used to measure employees' perceptions of the five core job characteristics. It is the most frequently used tool for measuring the job characteristics. The testing has proved that the Job Characteristics Model has certain effects on the employees' work behavioral outcomes.

Task design (also referred to as work design or job design) is a kind of management activity to specify the contents, Whether or not the task design is suitable will not only affect the employees' personal internal feelings but also affect the employees' external work behavior and performance. Itoh [5] proved that the important factor that affects the agent's ability to complete a number of tasks is the substitutability nature of jobs. Radhakrishnan [6] and other people developed an analysis framework on the basis of Principal-agent Theory to make a quantitatively economic analysis on the intrinsic motivating effect. The research showed that challenging could act as a motivation power and will optimize the risk sharing caused by the financial reward motivation system and disclose more information about the level of the efforts that the employees make. Zhang's study (2014) [7] indicated that a variety of task design will fill the information gaps among different tasks so as to increase the working efficiency. Oddvar and Trond [8] made an analysis on the work motivation problems rising from the situation that several tasks are processed. Schooner's research showed that diverse task designs are considered to be the most optimal solution only when the available performance measurement is not fully effective. Most of the studies mentioned above focus on analyzing how the task content design will boost the employees' motivation, but the task design itself is rarely assessed.

$\mathrm{Hu}$ (2009) [9] on the basis of the previous researches on the construction enterprise project managers, made an analysis with the utility function of the project managers and proposed an incentive mechanism for the project managers. In his view, the main factors, which will affect the motivations and should be considered in the utility function analysis, include: reasonable compensation needs, social status needs, right needs and self-actualization needs. Wang and Hong (2015) [10] concluded with a summary as below in their study of the Chinese enterprises. The basic framework system for the construction enterprise project managers' incentive and restraint includes: target management, internal empowerment, performance assessment, incentive mechanism and career path.

In summary, at present, the existing domestic researches on the job characteristics model mostly focus on the task design. It is generally summarized that the Job Characteristics Model can enhance the employees' working initiative and affects their creativity in the work. However, there is still not enough research on the influencing mechanism of the Job Characteristics Model on the specific type of employees and again there is not any research available on the application of JCM to the project manager work behavior. Regarding the research on the people like the project managers, most scholars would focus on their quality and selection process, or on the project managers' credit risk control. As you can see, there are very few measures about the psychological states, incentive and guidance for the project managers. This paper explores the influencing mechanism of the relevant dimensions of the JCM on the project managers' work behavior.

\section{THEORETICAL HYPOTHESIS}

\section{A. Hypotheses on the five demensions of job characteristics model on State-owned Enterprise Project Managers' performance}

Based on the analysis of the job characteristics model, the five core characteristics (dimensions) of the job can influence the employees' work emotions from different perspectives, then affect the employees' work behavior and ultimately affect their work outcomes (performance).

In theory, the task, for which the state-owned enterprise project managers are responsible, is managing the entire process of a project from the start to the end. In this process, there is a wide range of tasks for the project managers to complete, so the project managers are required to master various knowledge and skills, including planning, programming, design, construction, installation of water and electricity, finance, management and so on. The skill variety can be clearly found in the task of the project managers.

In addition to the skill variety, the other four characteristics (dimensions) cannot fully be found in the task of the state-owned enterprise project managers. Some construction projects have long duration and long time span, however, as per the appointment and dismissal mechanism for the state-owned enterprises' cadres, the appointment period for a project manager is about 3-5 years. Therefore, it is highly possible that the project managers have no chance to get involved in the entire process of a project' development and construction. In such case, the task identity will be limited.

The state-owned enterprises' investment in a project is often intervened by the government function institutions. The project is determined by the government or social needs. Some projects involving large state-owned assets investment, such as road construction, railway construction and bridge construction, have great impacts and high social value. Some projects involving small facilities construction, such as substation, supporting roads, school, have relatively low social value. Therefore, task significance is also a variable in the task of the state-owned enterprises.

According to the requirements from the State-owned Assets Supervision and Administration Commission, the stateowned enterprises generally adopt the collective decisionmaking mechanism. Therefore, the important investment, important changes, important adjustments and other issues alike should be submitted to the project meeting for discussion and research. In such case, the project managers have no rights to make decision on their own. In addition to the major events, the level of the autonomy that the project manager will be provided with to carry out the work is directly related to the management style and management mode of the enterprises' senior managers.

The state-owned enterprise project managers mainly get the information about their work performance from the senior managers who are directly in charge of the project. Therefore, 
whether or not the feedback will be timely given is also determined by the senior managers' management style.

Among the five core job characteristics/dimensions of the Job Characteristics Model, the project managers generally have the characteristic of skill variety, but as for the other four (task identity, task significance, autonomy and feedback), they are related to the actual tasks, the empowerment that they are given and the leadership style of the leaders who are in direct charge of them. Therefore, the following hypothesis is proposed and verified:

Hypothesis 1: The state-owned enterprise project managers' work feelings and work emotions are positively correlated with the task identity, task significance, autonomy and feedback of the task that they are responsible for.

In the state-owned enterprise project managers' work, the above four job characteristics have the same effect on the work feelings and work emotions of the state-owned enterprise project managers.

\section{B. A Hypothesis on the Incentive Effect of JCM-based Task Design on the State-owned Enterprise Project Managers}

The state owned enterprise is the main economy of the wholly state-owned or state-controlled enterprises. Thanks to its nature, objective and social responsibility, the state-owned enterprise has relatively stable and high business volume, pay system and income level. At the same time, the state-owned enterprise's project is generally large, will have impacts on the national economy and people's life and has high value and social status. All of these characteristics greatly appeal to the project management talents.

The nature of the state-owned enterprises, namely, "being state-owned", determines that the state-owned enterprise project managers should have relevant qualities and abilities that are required for the appointment and dismissal cadres from the party and government organs and the state-owned enterprises will pay more attention to their ideological and political work style, their length of service in the same type of enterprise, comprehensive management abilities and so on.

The way that the state-owned enterprises select the project managers is similar to the one that the party and government organs select the appointment and dismissal cadres. The project managers are determined through a series of procedures, including selection, organizational recommendation, examination, appointment, etc. Only the one who is outstanding and has comprehensive qualities and abilities can be qualified enough to serve as the state-owned enterprise project manager. This determines that the project managers from the state-owned enterprises are the best among the knowledge and technology project managers and equipped with abilities similar to the ones found in the knowledge staffs and operators. According to the principle that the responsibilities should match the empowerment, once appointed, the project managers will have high income, good work platform and high social status. On the basis of the factors mentioned above, the following hypothesis is proposed and verified:
Hypothesis 2: The work feelings and emotions play a mediating role between the JCM-based task design and the work behavior and performance of the state-owned enterprise project managers. Without considering the external material incentives, like salary, promotion and rewards, the JCM-based task design will encourage the state-owned enterprise project managers to make positive behaviors and improve their work performance.

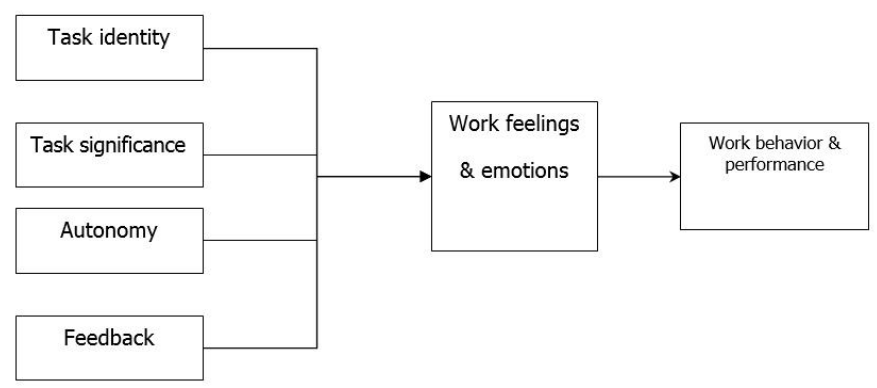

Fig. 1 The Relation Model between JCM and work behavior and performance

\section{DATA COLLECTION}

\section{A. Scales and Variable Measurements}

This paper uses questionnaire survey method to obtain data, and the investigation object is Xiamen real estate group project manager. In order to measure of major concepts, a customized questionnaire survey titled as Job Characteristics and Work Behavior is adopted. In order to have a better understanding of the work behavior and work performance, Work Role Performance designed by M.A GRIFFIN, Neal, A. \& Parker S.K. (2007) [11] is also used together with Organizational Citizenship Behavior (OCB), which was designed by Goyle-Shapiro J.A.M (2002) [12]. Job Characteristics and Work Behavior is specially designed for collecting the research object's work emotions and work feelings, and Work Role Performance and Organizational Citizenship Behavior are mainly used for collecting the research object's work behavior and work performance.

In order to make the job characteristic survey better fit the actual situations of the enterprises, a customized questionnaire titled as Job Characteristics and Work Behavior is adopted. It is designed on the basis of Five Core Job Characteristics Diagnosis Scale given by Fields D. L. (2004) [13], and a sample questionnaire survey called Job Characteristics Model - A Test based on Chinese Samples, which was designed by Yichi Zhang (2005) [14].

\section{B. Survey Process}

The author of this paper is working for the group mentioned in this paper. In order to make the survey results more accurate and prevent the results from being influenced by the respondents' subjective factors, such as guessing the purpose of these questionnaire and scales, the questionnaire was issued with the aid of the external consulting agency, and also, it is emphasized in the guideline that this questionnaire is designed only for management analysis and academic research there will be no impact on the respondents' personal work; no real personal information will be required in the questionnaire; the respondents are not required to disclose their personal 
information and sign their names; the investigators will strictly abide by the professional ethics; the survey data will be kept highly confidential and the personal information will never be disclosed. The questionnaire and scales were printed and recovered by the external consulting agency and ultimately were handed over to the author of this paper. A total of 70 questionnaires were issued and 64 were recovered with the recovery rate up to $91.4 \%$.

\section{Reliability and Validity Analysis}

This paper adopts a customized job characteristics scale, which consists of 28 questions. The characteristics surveyed in this scale include skill variety (7 questions), feedback (6 questions), task identity (4 questions), task significance (5 questions) and autonomy (6 questions). The reliability and validity of this scale is tested by using SPSS17.0 statistical software. The test result is 0.835 , which means that this scale has good reliability and the total scale explains $55.36 \%$ of the total variance, so this scale has good validity.

Work feelings and work emotions scale consists of 30 questions. 13 questions are for work feelings, including experienced meaningfulness in the job, confidence, selfdiscipline etc.; 17 questions are for work emotions, including work initiative, the sense of responsibility, etc.. The reliability and validity of this scale is tested by using SPSS19.0 statistical software. The test result is 0.812 , which means that this scale has good reliability and the total scale explains $56.228 \%$ of the total variance, so this scale has good validity.

Work behavior and work performance scale consists of 27 questions with 14 questions for work role performance and 13 questions for organizational citizenship behavior. The reliability and validity of this scale is tested by using SPSS17.0 statistical software. The test result is 0.94 , which means that this scale has good reliability and the total scale explains $65.086 \%$ of the total variance, so this scale has good validity.

\section{DATA ANALYSIS}

\section{A. Variable Correlation Analysis}

The Table I shows the correlations among the variables mentioned in this paper and from this table, the following points can be found:

a. Among the 5 dimensions of the Job Characteristics Model, in addition to the work skill variety, work feedback is significantly correlated with the work feelings with the correlation coefficient above 0.05 . Task identity, task significance and autonomy are significantly and positively correlated with work feelings.

b. The 5 dimensions (characteristics) of the Job Characteristics Model are all significantly and positively correlated with the work emotions.

c. Among the 5 dimensions of the Job Characteristics Model, in addition to the skill variety, the other 4 dimensions (feedback, task identity, task significance and autonomy) are all significantly and positively correlated with the organizational citizenship behavior.
TABLE I. VARIABLE CORRELATION ANALYSIS

\begin{tabular}{|c|c|c|c|c|}
\hline & $\begin{array}{c}\text { Work } \\
\text { feelings }\end{array}$ & $\begin{array}{c}\text { Work } \\
\text { emotions }\end{array}$ & $\begin{array}{c}\text { Organization } \\
\text { al citizenship } \\
\text { behavior }\end{array}$ & $\begin{array}{c}\text { Work role } \\
\text { performance }\end{array}$ \\
\hline Skill variety & 0.123 & $.229 * *$ & .096 & $0.159^{*}$ \\
\hline Feedback & $.161 *$ & $.360 * *$ & $.784 * *$ & $0.349 * *$ \\
\hline Task identity & $.258 * *$ & $.298 * *$ & $.382 * *$ & $0.269 * *$ \\
\hline $\begin{array}{c}\text { Task } \\
\text { significance }\end{array}$ & $.242 * *$ & $.440 * *$ & $.630 * *$ & $0.410 * *$ \\
\hline Autonomy & $0.231 * *$ & $.278 * *$ & $.569 * *$ & $0.293 * *$ \\
\hline Work feelings & 1 & $.710 * *$ & 0.115 & $847 * *$ \\
\hline $\begin{array}{c}\text { Work } \\
\text { emotions }\end{array}$ & $.710 * *$ & 1 & $0.311 * *$ & $976^{* *}$ \\
\hline $\begin{array}{l}\text { Organizational } \\
\text { citizenship } \\
\text { behavior }\end{array}$ & 0.115 & $0.311 * *$ & 1 & $0.273 * *$ \\
\hline $\begin{array}{c}\text { Work role } \\
\text { performance }\end{array}$ & $0.849 * *$ & $0.976 * *$ & $0.273 * *$ & 1 \\
\hline
\end{tabular}

d. Among the 5 dimensions of the Job Characteristics Model, the skill variety is significantly correlated with the work performance with the correlation coefficient above 0.05 . The other 4 dimensions (feedback, task identity, task significance and autonomy) are all significantly and positively correlated with the work role performance.

e. Work emotions are significantly correlated with the organizational citizenship behavior and work role performance, but work feelings are only significantly and positively correlated with work role performance.

Based on the analysis of the above 4 points, it can be seen that the variable correlation analysis results has primarily testified the hypothesis 1 mentioned in this paper that the state-owned enterprise project managers' work feelings (selfefficacy) and work emotions are positively correlated with the task identity, task significance, autonomy and feedback of the tasks that they take on. But whether or not the work feelings and work emotions as middle variables can have positively incentive effects on the state-owned enterprise project managers so as to improve their positive work behavior needs to be further testified.

\section{B. Regression Analysis}

In order to further examine the correlations and investigate whether the work feelings and work emotions can act as middle variables between the relevant dimensions of the Job Characteristics Model and work behavior and work performance, four types of regression analysis are made on the survey data by using SPSS19.0 statistical software. The following table illustrates the results of regression analysis. 
TABLE II.

The Results of RegRession ANALysis

\begin{tabular}{|c|c|c|c|c|c|c|c|c|c|c|}
\hline \multirow{3}{*}{$\frac{2}{2}$} & \multirow{2}{*}{ Target variable } & \multirow{3}{*}{$\mathrm{R}$ square } & \multirow{3}{*}{ Sig. } & \multicolumn{7}{|c|}{ Predictor variables } \\
\hline & & & & $x_{1}$ & $x_{2}$ & $x_{3}$ & $x_{4}$ & $x_{5}$ & $x_{6}$ & $x_{7}$ \\
\hline & $y$ & & & Skill variety & Feedback & $\begin{array}{l}\text { Task } \\
\text { identity }\end{array}$ & $\begin{array}{l}\text { Task } \\
\text { significance }\end{array}$ & Autonomy & $\begin{array}{l}\text { work } \\
\text { feelings }\end{array}$ & $\begin{array}{l}\text { work } \\
\text { emotions }\end{array}$ \\
\hline I & Work feelings & 0.379 & $0.000 *$ & $(0.062)$ & 0.575 & $(0.109)$ & 0.122 & 0.140 & & \\
\hline \multirow[t]{2}{*}{ II } & Work behavior & 0.276 & $0.000^{*}$ & $\begin{array}{l}(0.170) \\
0.036^{*}\end{array}$ & $\begin{array}{l}0.180 \\
0.054\end{array}$ & $\begin{array}{c}(0.075) \\
0.457\end{array}$ & $\begin{array}{l}0.122 \\
0.136\end{array}$ & $\begin{array}{c}0.215 \\
0.005^{*}\end{array}$ & & \\
\hline & $\begin{array}{c}\text { Work role } \\
\text { performance }\end{array}$ & 0.141 & $0.000^{*}$ & $\begin{array}{c}(0.071) \\
0.446\end{array}$ & $\begin{array}{c}0.190 \\
0.048^{*}\end{array}$ & $\begin{array}{c}(0.132) \\
0.164\end{array}$ & $\begin{array}{c}0.303 \\
0.000^{*}\end{array}$ & $\begin{array}{c}0.189 \\
0.015^{*}\end{array}$ & & \\
\hline \multirow{2}{*}{ III } & $\begin{array}{c}\text { Work role } \\
\text { performance }\end{array}$ & 0.231 & $0.000^{*}$ & & & & & & $\begin{array}{c}0.074 \\
0.000 *\end{array}$ & \\
\hline & & 0.330 & $0.000^{*}$ & & & & & & & $\begin{array}{c}0.120 \\
0.000 *\end{array}$ \\
\hline \multirow[t]{2}{*}{ IV } & Work behavior & 0.166 & $0.000^{*}$ & $\begin{array}{c}(0.170) \\
0.096\end{array}$ & $\begin{array}{c}0.135 \\
0.001 *\end{array}$ & $\begin{array}{c}(0.109) \\
0.287\end{array}$ & $\begin{array}{l}0.073 \\
0.482\end{array}$ & $\begin{array}{l}0.129 \\
0.115\end{array}$ & $\begin{array}{c}0.206 \\
0.036^{*}\end{array}$ & $\begin{array}{c}0.316 \\
0.000^{*}\end{array}$ \\
\hline & $\begin{array}{c}\text { Work role } \\
\text { performance }\end{array}$ & 0.302 & $0.000^{*}$ & $\begin{array}{c}(0.149) \\
0.091\end{array}$ & $\begin{array}{l}0.142 \\
0.158\end{array}$ & $\begin{array}{c}(0.060) \\
0.523\end{array}$ & $\begin{array}{l}0.159 \\
0.055\end{array}$ & $\begin{array}{c}0.175 \\
0.039^{*}\end{array}$ & $\begin{array}{c}0.201 \\
0.026^{*}\end{array}$ & $\begin{array}{c}0.205 \\
0.019 *\end{array}$ \\
\hline
\end{tabular}

1. According to the regression analysis I results,1) the five dimensions of the Job Characteristics Model can explain $37.5 \%$ of the variance for the state-owned enterprise project managers' work feelings, and meanwhile, feedback, autonomy and task significance can significantly and positively predict the work feelings of such people; 2) the five dimensions of the Job Characteristics Model can account for $40.7 \%$ of the variance in the state-owned enterprise project managers' work emotions, and meanwhile, feedback, task significance and autonomy can significantly predict the work emotions of such people. It can be concluded from these analysis results that the job characteristics model mentioned in this paper plays a significant role in predicting the work feelings of specific groups.

2. According to the regression analysis II results, 1) autonomy and feedback has significantly positive ability to predict the work behavior of the state-owned enterprise project managers, and the five dimensions of the job characteristics model can give an explanation to $27.6 \%$ of the variance in the state-owned enterprise project managers' work behavior; 2 ) task significance and autonomy can significantly predict the work emotions of the state-owned enterprise project managers, and the five dimensions of the job characteristics model can account for $14.1 \%$ of the variance in the state-owned enterprise project managers' work emotions.

3. According to the regression analysis $\mathbb{I}$ results, 1) work feelings can predict the work behavior of the state-owned

enterprise project managers with an explanation for $9.6 \%$ of the variance; 2) work feelings can predict the work role performance of the state-owned enterprise project managers with an explanation for $7.4 \%$ of the variance; 3) work emotions can predict the work behavior and work role performance of the state-owned enterprise project managers and explain respectively $18.1 \%$ and $12 \%$ of the variance.

4. According to the regression analysis IV results, the five dimensions of the job characteristics model and working feelings and emotion as predictor variables can explain respectively $16.6 \%$ and $30.2 \%$ of the variance in the stateowned enterprise project managers' work behavior and work role performance. The regression analysis results also show that the five dimensions of the job characteristics model and working feelings and emotions can predict the work behavior and work role performance of the state-owned enterprise project managers. The five dimensions of the job characteristics model, working feelings and work emotions, as a part of the factors that can affect the state-owned enterprise project managers' work behavior and work performance, already have significant predict effects on the state-owned enterprise project managers' work behavior and work performance. Again, there is a finding in this regression analysis that the effect that the feedback and autonomy has on the state-owned enterprise project managers' work behavior gets lower, while the effect that the task significance has on 
the state-owned enterprise project managers' work behavior is insignificant and the effect that the feedback and task significance has on the state-owned enterprise project managers' work role performance gets lower.

Summarizing the results of the above said four type of regression analysis can give us a rough statement that: 1) the five dimensions of the job characteristics model mostly can significantly predict the work feelings and work emotions of the state-owned enterprise project managers; 2) the work feelings and work emotions have extremely significant predict effects on the work behavior and work performance of the state-owned enterprise project managers. Through examining the effect that the independent variables (job characteristics model) have on the middle variables (work feelings and work emotions), the effect that the independent variables have on the target variables (work behavior and work role performance), the effect that the middle variables (work feelings and work emotions) have on the target variables (work behavior and work role performance), and the effect that the independent variables and middle variables have on the target variables, it can be seen that among the correlations between the job characteristics model and the state-owned enterprise project managers' work behavior and role performance, work feelings and work emotions plays a partial mediating role between the feedback, task significance, autonomy and the state-owned enterprise project managers' work behavior and work performance.

\section{Limitation}

The research done in this paper is inadequate. Firstly, in the use of the scale, on the one side, the measurement of the core dimensions of the job characteristics model and the measurement of the critical mental state of the employee, the scale was revised on the basis of the well-recognized scale and pre-test was done, but the measurement effect is not ideal; on the other side, in the measurement of the work behavior and work performance, this paper adopts the well-recognized foreign scales, there may be some bias when they are applied in China. Secondly, the data collection of this study is mainly based on a large state-owned enterprise in Xiamen, China. The sample is representative, but it still has some limitations in terms of the region and the enterprise type. In the future research, it would be better if more different enterprises and different regions could be covered.

\section{CONCLUSION}

On the basis of the Job Characteristics Model Theory, this paper examines the effect of the specific dimensions of the job characteristics model on the state-owned enterprise project managers' work emotions, work attitudes, work behavior and work role performance through the questionnaire survey, variable correlation analysis and regression analysis. It is finally proved that the JCM-based task design indeed has positive effects on the state-owned enterprise project managers' work behavior and work performance.

This paper proposes two hypotheses. Hypothesis 1: The state-owned enterprise project managers' work feelings and work emotions are positively correlated with the task identity, task significance, autonomy and feedback of the task that they are responsible for. In the state-owned enterprise project managers' work, the above four job characteristics have the same effect on the work feelings and work emotions of the state-owned enterprise project managers. Hypothesis 2: The work feelings and emotions play a mediating role between the JCM-based task design and the work behavior and performance of the state-owned enterprise project managers. Without considering the external material incentives, like salary, promotion and rewards, the JCM-based task design will encourage the state-owned enterprise project managers to make positive behaviors and improve their work performance. This paper makes researches on Xiamen Real Estate Group, a typical large state-owned enterprise in Xiamen, and the research results prove that hypothesis 1 is partially true. Namely, the state-owned enterprise project managers' work feelings and work emotions are positively correlated with the task identity, task significance, autonomy and feedback of the task that they are responsible for, but these four dimensions do not have the same effect on the state-owned enterprise project managers' work feelings and work emotions. The task identity will not impact the project managers' work feelings and work emotions as significantly as the other three dimensions (task significance, autonomy and feedback) do. However, the research results prove that hypothesis 2 is true. Work feelings and work emotions play a mediating role between the JCMbased task design and the work behavior and performance; and the JCM-based task design has positive effect on the stateowned enterprise project managers' work feelings and work emotions and will encourage them to make positive behaviors and improve work performance. All these findings offer valuable support for the state-owned enterprises to make effective incentive task design for the project mangers in the future.

\section{ACKNOWLEDGMENT}

I want to give my first and special thank you to my friends and colleagues. Their support and understanding through the process made it possible for me to have enough time to accomplish this paper. Thank everyone who helped me in this process.This paper is supported by YUNFE Project Grant YC2015D16.

\section{REFERENCES}

[1] F. Herzberg, "Work and the nature of man, Cleveland and New York: The Word Publishing Company," 1966, pp. 93-97.

[2] H.S. Lawrence, "Transfer Factor and Autoimmune Disease," Annals of the New York Academy of Sciences. 1965, pp. 56-60.

[3] M.R. Blood, and C.L. Hu, "Alienation, environmental characteristics, and worker responses," Journal of Applied Psychology. 1967, pp. 284290

[4] J.R. Hackman, and E.E. Lawler, "Employee reactions to job characteristics," Journal of Applied Psychology, 1971, pp. 259-28.

[5] K. Daido, and H. Itoh, "The Pygmalion effect : an agency model with reference dependent preferences," CESifo Working Paper, 2005, pp. 1444-1449.

[6] R. Suresh, and R. Joshua, "Job challenge as a motivator in a principalagent setting," European Journal of Operational Research. 1999, pp. 138-157.

[7] J. Zhang, "Culture and the Gender Gap in Competitive Inclination: Evidence from the Communist Experiment in China," Working Paper. University of Munich, 2014. 
[8] M. Oddvar, Kaarbøe, and E. Trond, "Career concerns, monetary incentives and job design," Scandinavian J.Econom, vol. 108, 2006, 299-316.

[9] Y. Hu, and J.T. Shi, "A study on the relationship between the effects of the organizational innovative climate and those of motivational preference on employees' innovative behavior," Management World, 2009 , pp. 88-104。

[10] J.J. Hong, C.Q. Wang and M. Kafouros, "The Role of the State in Explaining the Internationalization of Emerging Market Enterprises," British Journal of Management. 2015, pp. 45-62.

[11] M.A. Griffin, A. Neal, and S.K. Parker, "A new model of work role performance: Positive behavior in uncertain and interdependent contexts," Academy of management journal. 2007, pp. 327-347.
[12] S. Coyle, A.M. Jacqueline, and M. Parzefall, "Psychological contracts. In: Cooper, Cary L. and Barling, Julian," The SAGE handbook of organizational behavior. SAGE Publications, London, UK. 2002, PP. 17-34.

[13] D.L. Judge, and R.F. Piccolo, "Transformational and transactional leadership: A meta-analytic test of their relative validity," Journal of Applied Psychology. 2004, pp. 755-768.

[14] Y.C. Zhang, L.F. Wang, Y.M. Xiang, and C.W. Ten, "Power System Reliability Evaluation With SCADA Cybersecurity Considerations," IEEE Trans. Smart Grid. 2005, pp. 1707-1721. 